\title{
A Substantial and Unexpected Enhancement of Motion Perception in Autism
}

\author{
Jennifer H. Foss-Feig, ${ }^{1 \star}$ Duje Tadin, ${ }^{3 \star}$ Kimberly B. Schauder, ${ }^{4}$ and Carissa J. Cascio ${ }^{2,4}$ \\ ${ }^{1}$ Department of Psychology and Human Development, and ${ }^{2}$ Vanderbilt Kennedy Center, Vanderbilt University, Nashville, Tennessee 37203 , ${ }^{3}$ Center for \\ Visual Science, Department of Brain and Cognitive Sciences and Department of Ophthalmology, University of Rochester, Rochester, New York 14627, and \\ ${ }^{4}$ Department of Psychiatry, Vanderbilt University, Nashville, Tennessee 37212
}

\begin{abstract}
Atypical perceptual processing in autism spectrum disorder (ASD) is well documented. In addition, growing evidence supports the hypothesis that an excitatory/inhibitory neurochemical imbalance might underlie ASD. Here we investigated putative behavioral consequences of the excitatory/inhibitory imbalance in the context of visual motion perception. As stimulus size increases, typical observers exhibit marked impairments in perceiving motion of high-contrast stimuli. This result, termed "spatial suppression," is believed to reflect inhibitory motion-processing mechanisms. Motion processing is also affected by gain control, an inhibitory mechanism that underlies saturation of neural responses at high contrast. Motivated by these behavioral correlates of inhibitory function, we investigated motion perception in human children with ASD $(n=20)$ and typical development $(n=26)$. At high contrast, both groups exhibited similar impairments in motion perception with increasing stimulus size, revealing no apparent differences in spatial suppression. However, there was a substantial enhancement of motion perception in ASD: children with ASD exhibited a consistent twofold improvement in perceiving motion. Hypothesizing that this enhancement might indicate abnormal weakening of response gain control, we repeated our measurements at low contrast, where the effects of gain control should be negligible. At low contrast, we indeed found no group differences in motion discrimination thresholds. These low-contrast results, however, revealed weaker spatial suppression in ASD, suggesting the possibility that gain control abnormalities in ASD might have masked spatial suppression differences at high contrast. Overall, we report a pattern of motion perception abnormalities in ASD that includes substantial enhancements at high contrast and is consistent with an underlying excitatory/inhibitory imbalance.
\end{abstract}

\section{Introduction}

Dating from the earliest clinical observations (Kanner, 1943), atypical perceptual processing has been documented widely in autism spectrum disorder (ASD; Ben-Sasson et al., 2009). Perceptual differences likely play an important role in complex behavioral, social, and cognitive deficits that define ASD (Zwaigenbaum et al., 2005; Mottron et al., 2006; Samson et al., 2011). Therefore, working toward a mechanistic understanding of perceptual alterations might reveal key insights into the neural underpinnings of ASD. Much attention has focused on visual perception in ASD (Simmons et al., 2009). Both visual impairments, such as face perception deficits (Simmons et al., 2009), and enhancements, such as superior perception of local visual features (Dakin and Frith, 2005) and enhanced visual search

Received March 29, 2012; revised March 23, 2013; accepted April 1, 2013.

Author contributions: J.H.F.-F., D.T., and C.J.C. designed research; J.H.F.-F. and K.B.S. performed research;J.H.F.-F., D.T., K.B.S., and C..C. analyzed data; J.H.F.-F., D.T., and C.J.C. wrote the paper.

This work was supported by the National Eye Institute-National Institutes of Health (Core Grants P30 EY001319 and P30 EY08126, Grant R01 EY019295 to D.T., and Grant K01-MH090232 to C.J.C.) and the National Center for Research Resources-National Institutes of Health (Grant 1 UL1 RR024975). J.H.F.-F. was supported by an Autism Speaks Dennis Weatherstone Predoctoral Fellowship.

The authors declare no competing financial interests.

*J.H.F.-F. and D.T. contributed equally to this work.

Correspondence should be addressed to Jennifer H. Foss-Feig, $160123^{\text {rd }}$ Ave South, PMB \#552, Nashville, TN 37212. E-mail: jennifer.h.foss-feig@vanderbilt.edu.

DOI:10.1523/JNEUROSCI.1608-12.2013

Copyright $\odot 2013$ the authors $\quad 0270-6474 / 13 / 338243-07 \$ 15.00 / 0$
(Plaisted et al., 1998; Joseph et al., 2009), have been observed. However, these enhancements are largely specific to processing of static stimuli. The integrity of motion processing has been controversial. Whereas some studies suggest widespread impairments indicating broad dorsal stream abnormalities (Spencer et al., 2000; Pellicano et al., 2005), other research argues deficits occur only with "complex" moving stimuli such as biological motion (Bertone et al., 2003; Kaiser and Shiffrar, 2009).

A parallel line of research has focused on neurobiological causes of the ASD phenotype. One prominent model posits that an imbalance between excitatory and inhibitory neural mechanisms might explain widespread abnormalities in ASD (Rubenstein and Merzenich, 2003). Indeed, genetic, neuroanatomical, and neuroimaging evidence supports an increase in neural excitability. This change appears to be driven by reduced efficacy of the GABAergic system (Buxbaum et al., 2002; Fatemi et al., 2009; Oblak et al., 2010), although glutamatergic abnormalities may also contribute (Schmeisser et al., 2012).

Here, in the context of visual motion perception, we explored possible behavioral signatures of excitatory/inhibitory imbalance. Specifically, we investigated effects of stimulus size and contrast on motion perception in ASD. We showed previously that, for typical adults, as stimulus size increases, motion direction of high-contrast patterns becomes markedly harder to perceive (Tadin et al., 2003). This behavioral result, termed "spatial suppression," is believed to reflect center-surround inhibition, likely 
Table 1. Participant demographics

\begin{tabular}{|c|c|c|c|c|}
\hline \multirow[b]{2}{*}{ Variable } & \multicolumn{2}{|l|}{ Group means } & \multicolumn{2}{|l|}{ Statistics } \\
\hline & ASD & TD & tstatistic & $p$-value \\
\hline \multicolumn{5}{|l|}{ High-contrast experiment } \\
\hline Age (years) & $12.7 \pm 2.9$ & $12.4 \pm 3.1$ & 0.31 & 0.76 \\
\hline Full-scale IQ & $116.7 \pm 12.4$ & $107.9 \pm 15.1$ & 1.78 & 0.09 \\
\hline ADOS algorithm total ${ }^{a}$ & $15.7 \pm 4.6$ & - & - & - \\
\hline ADI-R summary score ${ }^{b}$ & $44.5 \pm 10.5$ & - & - & - \\
\hline \multicolumn{5}{|l|}{ Low-contrast experiment } \\
\hline Age (years) & $11.4 \pm 2.2$ & $10.7 \pm 2.4$ & 0.75 & 0.46 \\
\hline Full-scale IQ & $111.4 \pm 20.5$ & $116.7 \pm 18.2$ & -0.66 & 0.52 \\
\hline ADOS algorithm total & $12.6 \pm 3.3$ & - & - & - \\
\hline ADI-R summary score & $42.3 \pm 13.3$ & - & - & - \\
\hline
\end{tabular}

$\overline{{ }^{a} \text { Autism Diagnostic Observation Schedule (ADOS) algorithm total score (Gotham et al., 2007) summarizing commu- }}$ nication, social, and repetitive behavior domains.

${ }^{b}$ Autism Diagnostic Interview-Revised (ADI-R) score collapsed across algorithm domains for communication, reciprocal social interaction, and repetitive behavior.

within cortical area MT (Tadin et al., 2003; Churan et al., 2008; Tadin et al., 2011). Abnormally weak spatial suppression, reflected in reduced effects of increasing stimulus size, characterizes populations exhibiting deficits in cortical inhibition; for example, patients with schizophrenia (Tadin et al., 2006b), those with a history of major depression (Golomb et al., 2009), and older adults (Betts et al., 2005; Betts et al., 2009). Given evidence for an excitatory/inhibitory imbalance in ASD, we expected similar results in our population.

Motion processing is also affected by response gain control, an inhibitory mechanism underlying saturation of neural responses at high contrasts (Albrecht and Hamilton, 1982; Katzner et al., 2011). To detect possible abnormalities in response gain control, we examined motion direction discriminations at both low and high contrast. If gain control mechanisms are impaired in ASD (Pei et al., 2012), we expected that increasing stimulus contrast would have larger effects on participants with ASD. Finally, focusing on motion perception enabled us to address outstanding questions about the integrity of motion processing in ASD.

\section{Materials and Methods}

Subjects. We studied children and adolescents with ASD and typically developing (TD) controls between 8 and 17 years of age. A total of 20 participants with ASD (all male) and 26 TD controls ( 21 male) participated in the study. Thirty-two participants completed the high-contrast experiment (15 ASD and $17 \mathrm{TD}) ; 23$ participants completed the lowcontrast experiment (10 ASD and 13 TD). Five and four children overlapped across experiments for the ASD and TD groups, respectively. For both experiments, ASD and TD participants were matched for age and IQ score, as measured by the Wechsler Abbreviated Scales of Intelligence (Weschsler, 1999; Table 1). For children with ASD, diagnoses were confirmed with the Autism Diagnostic Observation Schedule (Lord et al., 2000) and the Autism Diagnostic Interview-Revised (Lord et al., 1994); all participants in the ASD group met the diagnostic criteria for both measures. Descriptive statistics for diagnostic measures also are reported in Table 1. Children in the TD group were free of psychiatric, learning, and neurological disorders and had no first-degree relatives with ASD. The protocol was approved by the Vanderbilt University Institutional Review Board. All participants and their parents gave written informed assent and consent, respectively, and all were paid for their participation.

High-contrast experiment. Stimuli were created in MATLAB and Psychophysics Toolbox (Brainard, 1997) and shown on a linearized monitor (24-inch Sony GDM-FW900 CRT, $1024 \times 640$ resolution, $120 \mathrm{~Hz}$ ). Viewing was binocular at $77 \mathrm{~cm}$ and was enforced using a chin rest. Ambient and background illumination were 0.9 and $56.3 \mathrm{~cd} / \mathrm{m}^{2}$.

Stimuli were drifting gratings (Fig. 1; 1 cycle/degree, $4 \%$, starting phase randomized) presented in a stationary two-dimensional raised cosine envelope, the radius of which defined the stimulus size. Stimulus
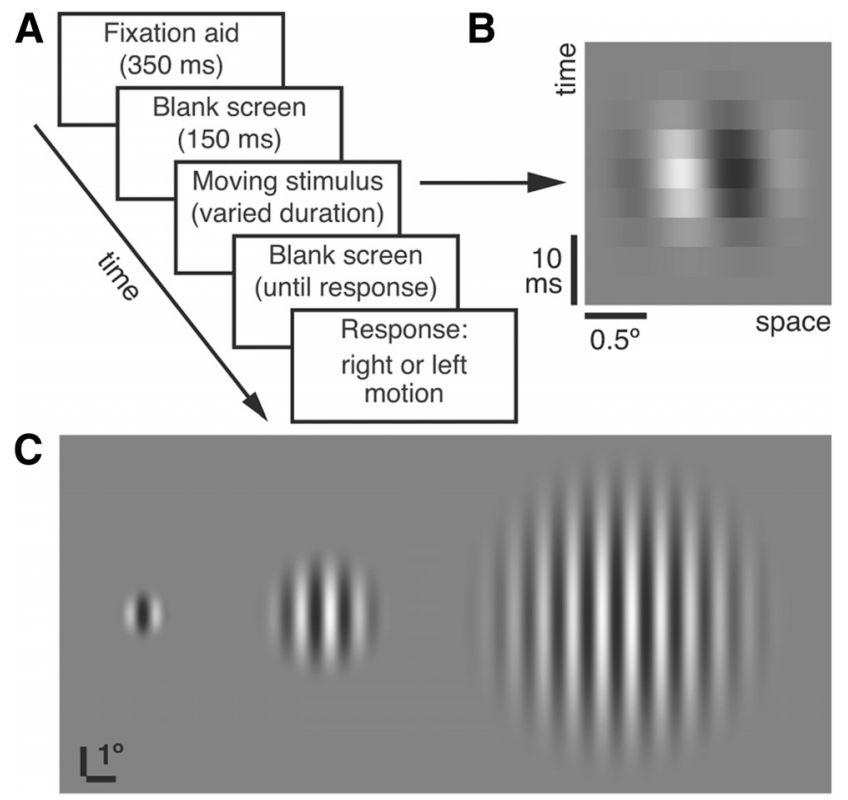

Figure 1. Stimuli and task. $\boldsymbol{A}$, Sequence of events constituting a single trial. $\boldsymbol{B}$, Space-time illustration showing a small stimulus $\left(1^{\circ}\right)$ moving to the right. The depicted duration ( $\left.25.6 \mathrm{~ms}\right)$ equals the average ASD threshold for this condition at high contrast (Fig. 2A). C, Stimulus sizes used in the study (radius $=1^{\circ}, 2.5^{\circ}$, and $6^{\circ}$ ). Only one stimulus was shown per trial.

contrast was $98 \%$. For all stimuli, the temporal envelope was a hybridGaussian (Tadin et al., 2011). Specifically, for very brief stimuli $(\sigma<15$ $\mathrm{ms}$ ), the temporal contrast envelope was Gaussian. Longer temporal envelopes were trapezoid-like: flanks were half-Gaussians and the central portion was set to the maximum contrast. Fine temporal precision was obtained by adjusting the SD of half-Gaussian flanks (with a constraint of $\sigma<15 \mathrm{~ms}$ ) and transferring "excess" contrast to the flat central portion. This hybrid envelope allowed fine temporal precision of brief stimuli and avoided protracted fade-in/fade-out periods associated with prolonged temporal Gaussians. Gaussian flanks allow subframe sampling (a temporal equivalent of subpixel sampling), permitting accurate presentation of brief stimuli using only a few monitor frames (Tadin et al., 2006a; Lappin et al., 2009). Stimulus duration was defined as the width at half-height of the temporal envelope.

The participants' task was to discriminate motion direction of briefly presented moving gratings (Fig. $1 A, B$ ). For each trial, a stimulus was presented at the central location, with its size chosen pseudorandomly. Participants indicated the perceived direction (left or right) by a key press. Auditory feedback followed correct responses. The subsequent trial started $1 \mathrm{~s}$ after each response. Participants were instructed to fixate on the center of the screen. To facilitate fixation, we used the following sequence: a fixation circle $\left(0.8^{\circ}\right.$ radius $)$ appeared after each key press response and, $500 \mathrm{~ms}$ later, the circle shrank to $0.13^{\circ}$ over $100 \mathrm{~ms}$, remained at that size for $250 \mathrm{~ms}$, and then disappeared $150 \mathrm{~ms}$ before stimulus onset. Based on our subjective impressions and feedback from child participants, this dynamic sequence was very effective in guiding eye gaze to the center of the screen before the onset of a static fixation cross. It is important to note that no dynamic fixation stimuli appeared within the $400 \mathrm{~ms}$ preceding stimulus onset; a conventional fixation target followed by a blank screen was presented during that time.

Three conditions, varying in stimulus size, were used (Fig. 1C): small ( $1^{\circ}$ radius), medium $\left(2.5^{\circ}\right.$ radius), and large ( $6^{\circ}$ radius). These stimulus sizes were selected on the basis of previous results (Tadin et al., 2003) with the goal of including both small stimuli for which performance is high and large stimuli for which spatial suppression reduces motion sensitivity. Task difficulty was controlled by adjusting the stimulus duration to evaluate the minimum stimulus presentation duration for which each participant could reliably judge motion direction at a given stimulus size. Specifically, psychophysical thresholds were measured by adaptive QUEST staircases that adjusted $\log _{10}$ (stimulus duration) and 


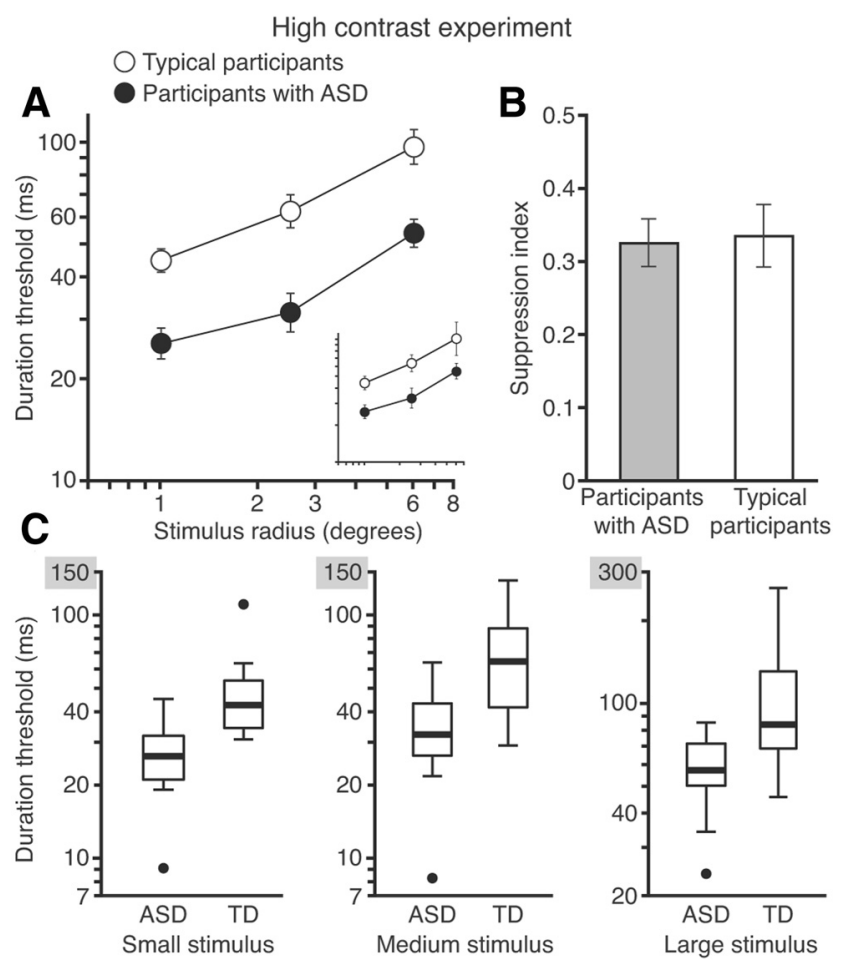

Figure 2. Motion discrimination performance and spatial suppression strength at high contrast. $A$, Comparison of duration thresholds for discriminating high-contrast motion in participants with ASD and TD. Results reveal a substantial enhancement of motion perception in ASD that is independent of stimulus size. The insert shows data for participants who completed both low- and highcontrast experiments. $\boldsymbol{B}$, Suppression index scores (computed as the difference of $\log _{10}$ duration thresholds for large versus small motion stimuli) do not differ between ASD and TD groups. Error bars in $\boldsymbol{A}$ and $\boldsymbol{B}$ represent SEM. C, Box-and-whisker plots showing robust separation of results for participants with ASD and TD. Thick lines indicate median performance. Boxes indicate the interquartile range and whiskers show the data range exclusive of outliers. Outliers (filled circles) are defined as data points $>1.5$ times the interquartile range beyond the first and the third quartiles. For each stimulus size, the median TD performance approximately equals the threshold exhibited by the worstperforming participant with ASD. Note the different $y$-axis range for the rightmost plot.

converged to $82 \%$ correct (Watson and Pelli, 1983). After a 66-trial practice block, thresholds were obtained in three successive 132-trial blocks, separated by breaks. Each block contained six interleaved staircases and yielded two thresholds for each of three size conditions (i.e., small, medium, and large). Therefore, across three blocks of trials, we estimated 18 thresholds (i.e., six for each stimulus size). For each participant, the lowest and highest of the six duration thresholds for each stimulus size were eliminated; the average of the remaining four measurements constituted a threshold estimate. This helped to eliminate occasional extreme values. Participants completed all trials within a single session (lasting $\sim 25 \mathrm{~min}$ ) and were monitored by an examiner throughout.

Low-contrast experiment. The low-contrast experiment was identical to the above-described high-contrast experiment, except that the stimulus contrast was lowered to $2.9 \%$. The motivation for this experiment was to determine whether the results we found at high contrast, namely a pronounced ASD enhancement in motion perception (Fig. 2), could be generalized to low-contrast stimuli. See Discussion for additional information.

Data analysis. First, to assess the reliability of our measurements, for each of six conditions (two experiments with three size conditions in each), we computed split-half reliabilities for the ASD and TD groups. The average split-half reliabilities for participants with ASD and TD were 0.989 and 0.984 , respectively. These high interparticipant correlations show that our approach was very reliable at measuring motion sensitivity in children and adolescents.

To quantify spatial suppression strength, we calculated the suppression index, defined as the difference of thresholds for large versus small stimuli (Tadin et al., 2003; Betts et al., 2005; Tadin et al., 2006b; Betts et al., 2009; Tadin et al., 2011). Specifically, suppression index $=\log _{10}$ (large stimulus threshold $)-\log _{10}$ (small stimulus threshold). Note that this definition of the suppression index assumes that the thresholds are expressed in milliseconds (as reported in the Results section). Using this convention, higher suppression index values correspond to stronger spatial suppression (i.e., worsening of performance with increasing stimulus size), whereas negative values indicate spatial summation (i.e., an improvement with increasing size). Typically, spatial suppression is found at high contrast and its strength decreases as the contrast decreases. At low contrast, spatial summation is typically found (Tadin et al., 2003). It is worth noting that the suppression index is not a log-transform measure, but rather is simply the difference between the two thresholds. The QUEST staircase procedure is designed to "work" in the log space (Watson and Pelli, 1983), directly estimating $\log _{10}$ (threshold). In other words, data presented here are not log transformed, but rather were natively estimated in the log space (for ease of interpretation, thresholds are reported in milliseconds in the Results section and were obtained by calculating the $10^{\wedge}$ threshold).

Before conducting the statistical analysis, we confirmed that datasets did not significantly deviate from the normal distribution and that variances of ASD and TD datasets did not significantly differ from each other. To analyze duration threshold results for each experiment, group differences were evaluated using a 2 (group) $\times 3$ (stimulus size) repeatedmeasures ANOVA. Greenhouse-Geisser correction for nonsphericity was used for low-contrast data only. Follow-up analyses with IQ score and age entered as covariates yielded similar results to the primary motion discrimination and suppression index analyses, with all group differences remaining highly significant. Results also held when female participants were eliminated from the control group to match the groups for gender. To analyze the results between low- and high-contrast experiments, we conducted a 2 (group) $\times 2$ (contrast) ANOVA, with repeated, within-subjects measures on contrast. For this analysis, only the subset of ASD and TD participants that completed both high- and low-contrast experiments was included. Finally, to evaluate the clinical relevance of our findings, exploratory correlational analyses were conducted to examine whether task performance was related to clinical symptoms in the ASD group.

\section{Results}

\section{High-contrast experiment}

For high-contrast stimuli, both the TD and ASD groups exhibited the characteristic increase in direction discrimination thresholds with increasing stimulus size, a result indicative of spatial suppression of large moving stimuli (Fig. $2 A ; F_{(2,30)}=98.8, p<$ $\left.10^{-9}\right)$. Specifically, as stimulus size increased, participants in both groups required longer stimulus exposure times to correctly identify motion direction. This threshold increase with increasing stimulus size, however, did not differ between groups $\left(F_{(2,30)}=0.72, p=0.49\right)$; both groups showed equal spatial suppression strength. This result was further supported by a between-groups comparison of the suppression index (Fig. 2B; $t_{30}=-0.18, p=0.86$ ).

The surprising result was the substantial superiority of participants with ASD in their ability to discriminate motion direction (Fig. $2 A ; F_{(1,30)}=19.2, p=0.0001$ ). Specifically, across all stimulus sizes, we found a consistent, twofold decrease in thresholds for participants with ASD. This ASD advantage was considerable and was not driven by outliers: for all three stimulus sizes, the third quartile for the ASD group was approximately equal to the first quartile for the TD group (Fig. 2C). Moreover, the performance of the worst participant with ASD approximately equaled the median TD performance for each stimulus size (Fig. 2C). The main finding from the high-contrast experiment was that participants with ASD were markedly better at discriminating motion direction across all stimulus sizes. 
Low contrast experiment
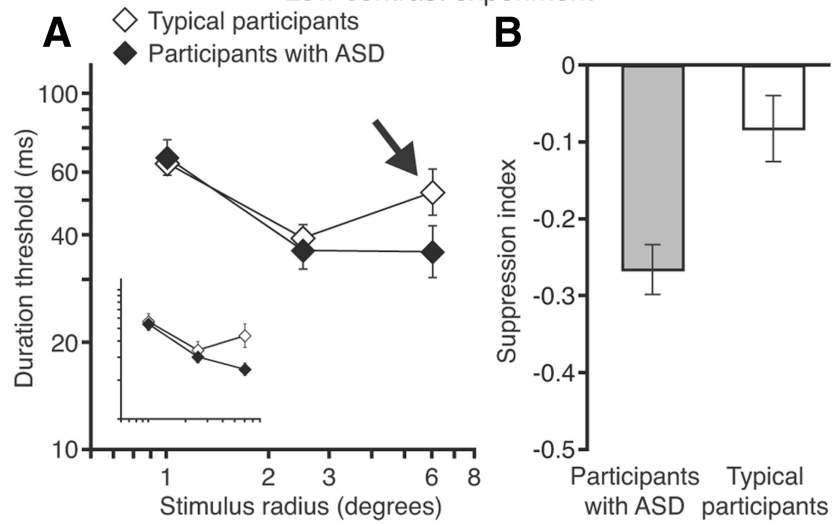

Figure 3. Motion discrimination performance and spatial summation strength at low contrast. $A$, Comparison of duration thresholds for discriminating low-contrast motion in participants with ASD and TD. Unlike high-contrast results, there are no substantial differences between groups except an increase in the TD (but not ASD) thresholds for the largest stimulus size (shown by the arrow). The insert shows data for participants who completed both low- and high-contrast experiments. $\boldsymbol{B}$, Suppression index scores were negative for both groups, indicating spatial summation at low contrast. However, participants with TD also exhibited signs of spatial suppression ( $\boldsymbol{A}$, arrow). This was evident as a significant difference in suppression index score between the two groups. Error bars in both panels represent SEM.

\section{Low-contrast experiment}

For low-contrast stimuli, we saw the characteristic decrease in direction discrimination thresholds with increasing stimulus size (Fig. $3 A ; F_{(2,21)}=43.2, p=10^{-5}$ ). This result indicates spatial summation, an improvement in motion perception with increasing stimulus size (Anderson and Burr, 1991; Tadin et al., 2003). Contrary to our findings at high contrast, we found no overall group differences in participants' ability to discriminate motion direction at low contrast $\left(F_{(1,21)}=0.83, p=0.37\right)$. In another contrast-specific finding, the effect of increasing stimulus size differed between the two groups, as indicated by a significant group by stimulus size interaction $\left(F_{(2,21)}=6.50, p=0.011\right)$. Participants with TD exhibited the beginning signs of spatial suppression, reflected in a threshold increase for the largest stimulus size (Fig. $3 A$, arrow), similar to what was observed in both groups at high contrast. Conversely, participants with ASD showed size-dependent improvements that were consistent with spatial summation across the entire range of stimulus sizes used. This result is further supported by the significant group difference in the suppression index for low-contrast stimuli (Fig. $\left.3 B ; t_{21}=-2.44, p=0.024\right)$.

To summarize the low-contrast findings, we found no overall group differences in motion discrimination thresholds paired with smaller suppression indices in participants with ASD. This pattern of results differed from that observed at high contrast, revealing that enhanced motion perception in participants with ASD is limited to high-contrast stimuli. We will return to these differences between high- and low-contrast results in the Discussion. The observed pattern of results is evident even if we only consider participants who completed both experiments (Fig. 2A, Fig. $3 A$, inserts). This subset of participants included only males; ASD and TD groups remained matched for age and IQ score.

\section{Effects of stimulus contrast}

Another way to examine these results is to consider the effect of contrast. Specifically, we aimed to determine how increasing stimulus contrast affects motion perception in participants with ASD and TD. Here, we focused on the performance for the small-

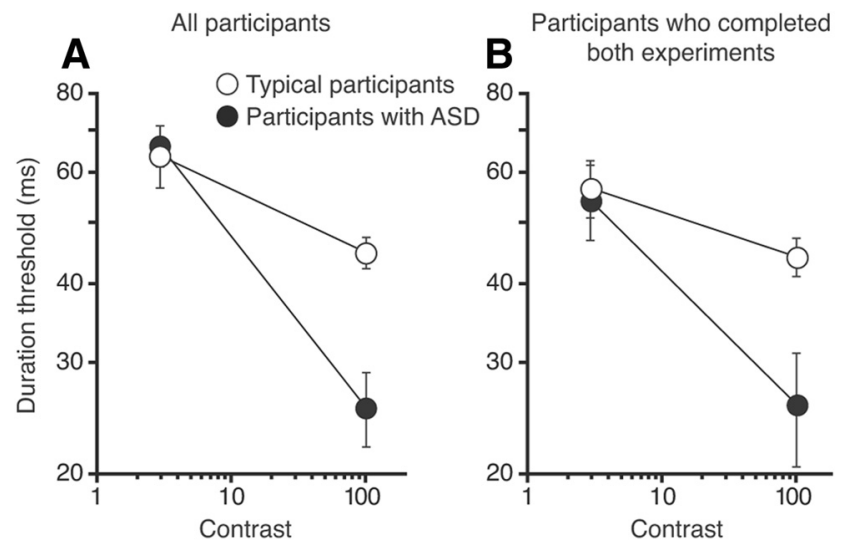

Figure 4. Effects of contrast on motion direction discriminations for participants with TD and ASD. $A$, Effect of increasing stimulus contrast on direction discrimination thresholds for small moving stimuli. This plot is constructed by combining the leftmost data points in Figure $2 A$ and Figure $3 A$ and replotting these data as a function of stimulus contrast. $\boldsymbol{B}$, Same as in $\boldsymbol{A}$, except that only data from participants who completed both low- and high-contrast experiments are included. Error bars in both panels represent SEM.

est stimulus size, a size at which the effects of spatial suppression should be minimal regardless of contrast level (Tadin et al., 2003). This allowed us to better isolate contrast-dependent mechanisms. For the smallest size, the two groups were nearly identical in their duration thresholds at low contrast (Fig. 4A). Increasing contrast improved performance for both groups, but this improvement was considerably stronger for participants with ASD than for those with TD (40.8 vs $19.1 \mathrm{~ms}$, respectively). As a result, at high contrast, participants with ASD performed substantially better than those with TD. Comparing group performance across contrast levels, participants with ASD exhibited greater performance gains with increasing contrast. For statistical analysis, we only considered participants who completed both experiments (Fig. 4B). These results were consistent with the full dataset, revealing a significant main effect of contrast $\left(F_{(1,7)}=\right.$ $\left.534.3, p=10^{-7}\right)$ and a significant group-by-contrast interaction $\left(F_{(1,7)}=16.13, p=0.005\right)$.

\section{Relations with ASD symptom measures}

Within the ASD group, exploratory analyses evaluated the relation between motion thresholds and summary scores from both direct observation (i.e., the Autism Diagnostic Observation Schedule) and parent report (i.e., the Autism Diagnostic Interview-Revised) measures of ASD symptomatology. At high contrast, neither the Autism Diagnostic Observation Schedule nor the Autism Diagnostic Interview-Revised summary scores were correlated with thresholds for any stimulus size (all $|r|<$ $0.43, p>0.12$ ). At low contrast, we found a significant correlation between Autism Diagnostic Interview-Revised scores and thresholds for discriminating motion of medium size stimuli ( $r=$ $-0.68, p=0.032$; other $|r|<0.58, p>0.077)$. However, given the large number of correlations conducted (12 total) and the lack of group differences at that size (Fig. $3 A$ ), we conclude that there is no systematic relationship between ASD symptomatology and thresholds for perceiving motion direction. Given these findings, superior motion perception abilities at high contrast appear to cleanly distinguish participants with ASD from those without, independent of the severity of ASD symptoms. Therefore, motion perception enhancement for high-contrast stimuli may reflect a state, rather than trait, marker of ASD. 


\section{Discussion}

Our study had two main empirical findings. First, we found a substantial enhancement of motion perception in ASD. To our knowledge, this is the first report of superior motion discrimination in ASD; previous reports noting enhanced visual processing were restricted to stationary stimuli (Dakin and Frith, 2005). Second, as detailed below, we report a pattern of abnormalities that is consistent with an underlying excitatory/inhibitory imbalance in ASD.

\section{Motion perception enhancement}

Our finding of superior motion perception in ASD is inconsistent with prior reports. What could explain this discrepancy? Our stimuli and task differed in three key ways. First, we used highly visible, luminance-defined (first-order) motion stimuli, whereas motion perception deficits in ASD are typically found with more complex stimuli, such as biological and texture-defined (secondorder) motion (Bertone et al., 2003). Small improvements have been reported for perceiving static luminance-defined stimuli (Bertone et al., 2005); however, for the moving version of the same stimuli, participants with ASD exhibited intact, but not enhanced, performance (Bertone et al., 2003). Using similar stimuli, we found considerable motion perception enhancements in ASD. Therefore, stimulus differences alone cannot explain our findings.

Second, we estimated duration thresholds, measuring the minimum stimulus viewing time that subjects needed to correctly perceive motion direction. Effectively, duration thresholds estimate how quickly the visual system accumulates task-relevant stimulus information (Gold and Shadlen, 2000). Therefore, one possible hypothesis is that ASD is associated with unusually quick accumulation of low-level motion information. Supporting this hypothesis, Davis et al. (2006) found that ASD performance on a motion coherence task was impaired for long, but not short, stimulus durations. Analogous results were reported with static stimuli, with which improvements were found only with brief exposure durations (Caron et al., 2006). More broadly, subjects with ASD tend to excel in perceptual tasks in which processing speed is important (Scheuffgen et al., 2000; Joseph et al., 2009; Brock et al., 2011). Stimulus duration might be important in that, as presentation duration becomes longer, attentional limitations (Burack, 1994) and other cognitive deficits (Garretson et al., 1990; Bennetto et al., 1996) may increasingly factor into and impair task performance in ASD. In addition, a recent report linked ASD with noisy cortical responses to sustained motion stimuli (Dinstein et al., 2012). In this study, attention was controlled, indicating that perceptual processing itself in ASD is noisy. It is possible that brief stimuli, such as those used in our experiment, are less affected by this broad decrease in response reliability (Churchland et al., 2010). Brief stimulus durations cannot, however, fully explain our results because we found enhancements only at high contrast.

Third, we measured motion discriminations at both high and low contrast. In motion perception, performance typically improves with increasing contrast, but saturates at high contrast (Nakayama and Silverman, 1985; Blake et al., 2006). Our results show that both the ASD and TD groups improved with contrast. However, this improvement was considerably larger for participants with ASD (Fig. 4), suggesting deficient contrast saturation in ASD. This would allow continued performance gains at high contrast above and beyond gains made with contrast by TD participants. This conclusion is consistent with a recent visual evoked potential study finding less contrast saturation in partic- ipants with ASD (Pei et al., 2012). Similar results were found in epilepsy (Porciatti et al., 2000; Tsai et al., 2011), which is notable given the links between epilepsy and ASD (Tuchman and Cuccaro, 2011). Lack of contrast saturation is a signature effect of impaired response gain control, a neural mechanism that is sensitive to changes in inhibitory function (Katzner et al., 2011).

In sum, although our use of first-order motion and brief stimulus durations allowed us to avoid stimuli in which participants with ASD exhibit difficulty, the inclusion of high-contrast stimuli was likely critical in revealing motion perception enhancements in ASD. The observed enhancement at high contrast would not be detectable by conventional approaches to measuring motion perception, which tend to rely on contrast or coherence threshold measurements. These well established approaches have the disadvantage of being restricted to barely visible or highly noisy stimuli and thus can miss effects that change with stimulus visibility (Tadin et al., 2003). Indeed, the above described behavioral ASD studies used either coherence or contrast thresholds, precluding measurement of motion perception for highly visible, noise-free stimuli that would be affected by contrast saturation differences.

An alternative explanation for our findings is that participants with ASD used position cues to perform this task. Perceived position of moving objects appears slightly shifted in the direction of their motion (Whitney, 2002), providing stationary cues to the stimulus motion direction. If participants with ASD relied on apparent position displacements to make motion direction judgments and if that strategy was superior to relying on perceived motion direction, we would expect an ASD advantage. However, our contrast-specific results are inconsistent with this notion because motion-induced position shifts occur both at high and low contrast (Bressler and Whitney, 2006). In addition, to account for large group difference at high contrast, nearly all participants with ASD would have had to ignore task instructions and adopt a position-based strategy.

\section{Implications regarding an excitatory/inhibitory imbalance in ASD}

Our initial motivation for this study was to examine spatial suppression in ASD and, as commonly defined, we found no deficits. Specifically, despite large differences in overall motion sensitivity at high contrast, both groups showed similar patterns of threshold increases with increasing stimulus size (Fig. 2A). This finding differentiates ASD from other populations with known inhibitory deficits: subjects with schizophrenia, depression history, and old age all exhibit reduced spatial suppression on this task (Betts et al., 2005; Tadin et al., 2006b; Golomb et al., 2009). If considered alone, this finding appears inconsistent with the notion of a widespread excitatory/inhibitory imbalance in ASD (a broad reduction in inhibitory function should affect associated behavioral phenomena such as spatial suppression). Such a conclusion would be consistent with a recent binocular rivalry study finding no evidence for excitatory/inhibitory imbalance in adults with ASD (Said et al., 2013). However, here we consider another explanation. A widespread excitatory/inhibitory imbalance would naturally affect functioning of a variety of neural mechanisms. Therefore, in some cases, separate effects of excitatory/inhibitory imbalance may functionally cancel each other out, resulting in no detectable changes at the behavioral level. As outlined next, we speculate that intact spatial suppression at high contrast in ASD may be one of those cases.

Motion perception exhibits two nonlinear effects that are relevant to this study: spatial suppression and contrast saturation. 
These behavioral effects likely reflect neural mechanisms of center-surround suppression (Tadin et al., 2003) and response gain control (Albrecht and Hamilton, 1982), respectively. Both mechanisms might be affected by an excitatory/inhibitory imbalance (Katzner et al., 2011; Tadin et al., 2011), weakening as the relative efficacy of inhibitory processes declines. At high contrast, reduced contrast gain control in ASD would increase the effective stimulus contrast, a change that should result in stronger spatial suppression in ASD (Tadin et al., 2003). Our failure to find such a result suggests that this effect may have been offset by weakening of spatial suppression in ASD driven by reduced centersurround inhibition. This explanation, we must admit, is currently speculative and arguably not the most parsimonious. Therefore, future work will need to better characterize spatial suppression and contrast gain control in ASD, both in motion perception and in other visual domains. We do, however, note that this account of our spatial suppression results also explains better-than-normal motion perception of high-contrast stimuli in ASD (as described above), as well as being consistent with our low-contrast results. Specifically, at 3\% contrast, the effects of response gain control should be negligible (Katzner et al., 2011). Indeed, the dramatic group difference in motion discriminations at high contrast did not generalize to low-contrast stimuli. However, with group performances relatively equal, we did observe a difference in the suppression index at low contrast: TD children exhibited signs of spatial suppression, whereas those with ASD showed only spatial summation (Fig. 3A). This again supports the hypothesis that the excitatory/inhibitory balance is atypical in ASD.

\section{Conclusions}

We report a new perceptual enhancement in ASD: a substantial superiority at perceiving direction of briefly presented, highcontrast moving stimuli. This enhancement suggests abnormal contrast gain control in ASD, a conclusion consistent with an underlying excitatory/inhibitory imbalance. Although we did not find reduced spatial suppression at high contrast, we speculate that changes in suppression strength were masked by changes in gain control. At low contrast, children with ASD exhibited abnormally weak spatial suppression relative to TD controls.

More broadly, we introduce a new paradigm for behavioral study of ASD that is sensitive to underlying deficits, but also includes conditions in which participants with ASD reliably outperform their typical counterparts. A paradigm in which underlying deficits lead to enhanced performance provides a robust index of the perceptual process being examined, in which differences are unlikely to be explained by concurrent, confounding differences between groups (e.g., attention, motivation). Future exploration using similar paradigms holds promise for further elucidating the nature of enhanced perception in ASD, which may provide a platform for developing novel intervention strategies.

\section{References}

Albrecht DG, Hamilton DB (1982) Striate cortex of monkey and cat: contrast response function. J Neurophysiol 48:217-237. Medline

Anderson SJ, Burr DC (1991) Spatial summation properties of directionally selective mechanisms in human vision. J Opt Soc Am A 8:1330-1339. CrossRef Medline

Bennetto L, Pennington BF, Rogers SJ (1996) Intact and impaired memory functions in autism. Child Dev 67:1816-1835. CrossRef Medline

Ben-Sasson A, Hen L, Fluss R, Cermak SA, Engel-Yeger B, Gal E (2009) A meta-analysis of sensory modulation symptoms in individuals with autism spectrum disorders. J Autism Dev Disord 39:1-11. CrossRef Medline
Bertone A, Mottron L, Jelenic P, Faubert J (2003) Motion perception in autism: a "complex" issue. J Cogn Neurosci 15:218-225. CrossRef Medline

Bertone A, Mottron L, Jelenic P, Faubert J (2005) Enhanced and diminished visuo-spatial information processing in autism depends on stimulus complexity. Brain 128:2430-2441. CrossRef Medline

Betts LR, Taylor CP, Sekuler AB, Bennett PJ (2005) Aging reduces centersurround antagonism in visual motion processing. Neuron 45:361-366. CrossRef Medline

Betts LR, Sekuler AB, Bennett PJ (2009) Spatial characteristics of centersurround antagonism in younger and older adults. J Vis 9:25.1-25.15. CrossRef Medline

Blake R, Tadin D, Sobel KV, Raissian TA, Chong SC (2006) Strength of early visual adaptation depends on visual awareness. Proc Natl Acad Sci U S A 103:4783-4788. CrossRef Medline

Brainard DH (1997) The psychophysics toolbox. Spat Vis 10:433-436. CrossRef Medline

Bressler DW, Whitney D (2006) Second-order motion shifts perceived position. Vision Res 46:1120-1128. CrossRef Medline

Brock J, Xu JY, Brooks KR (2011) Individual differences in visual search: relationship to autistic traits, discrimination thresholds, and speed of processing. Perception 40:739-742. CrossRef Medline

Burack JA (1994) Selective attention deficits in persons with autism: preliminary evidence of an inefficient attentional lens. J Abnorm Psychol 103: 535-543. CrossRef Medline

Buxbaum JD, Silverman JM, Smith CJ, Greenberg DA, Kilifarski M, Reichert J, Cook EH Jr, Fang Y, Song CY, Vitale R (2002) Association between a GABRB3 polymorphism and autism. Mol Psychiatry 7:311-316. CrossRef Medline

Caron MJ, Mottron L, Berthiaume C, Dawson M (2006) Cognitive mechanisms, specificity and neural underpinnings of visuospatial peaks in autism. Brain 129:1789-1802. CrossRef Medline

Churan J, Khawaja FA, Tsui JM, Pack CC (2008) Brief motion stimuli preferentially activate surround-suppressed neurons in macaque visual area MT. Curr Biol 18:R1051-R1052. CrossRef Medline

Churchland MM, Yu BM, Cunningham JP, Sugrue LP, Cohen MR, Corrado GS, Newsome WT, Clark AM, Hosseini P, Scott BB, Bradley DC, Smith MA, Kohn A, Movshon JA, Armstrong KM, Moore T, Chang SW, Snyder LH, Lisberger SG, Priebe NJ, et al. (2010) Stimulus onset quenches neural variability: a widespread cortical phenomenon. Nat Neurosci 13:369378. CrossRef Medline

Dakin S, Frith U (2005) Vagaries of visual perception in autism. Neuron 48:497-507. CrossRef Medline

Davis RA, Bockbrader MA, Murphy RR, Hetrick WP, O’Donnell BF (2006) Subjective perceptual distortions and visual dysfunction in children with autism. J Autism Dev Disord 36:199-210. CrossRef Medline

Dinstein I, Heeger DJ, Lorenzi L, Minshew NJ, Malach R, Behrmann M (2012) Unreliable evoked responses in autism. Neuron 75:981-991. CrossRef Medline

Fatemi SH, Reutiman TJ, Folsom TD, Thuras PD (2009) GABA(A) receptor downregulation in brains of subjects with autism. J Autism Dev Disord 39:223-230. CrossRef Medline

Garretson HB, Fein D, Waterhouse L (1990) Sustained attention in children with autism. J Autism Dev Disord 20:101-114. CrossRef Medline

Gold JI, Shadlen MN (2000) Representation of a perceptual decision in developing oculomotor commands. Nature 404:390-394. CrossRef Medline

Golomb JD, McDavitt JR, Ruf BM, Chen JI, Saricicek A, Maloney KH, Hu J, Chun MM, Bhagwagar Z (2009) Enhanced visual motion perception in major depressive disorder. J Neurosci 29:9072-9077. CrossRef Medline

Gotham K, Risi S, Pickles A, Lord C (2007) The Autism Diagnostic Observation Schedule: revised algorithms for improved diagnostic validity. J Autism Dev Disord 37:613-627. CrossRef Medline

Joseph RM, Keehn B, Connolly C, Wolfe JM, Horowitz TS (2009) Why is visual search superior in autism spectrum disorder? Dev Sci 12:10831096. CrossRef Medline

Kaiser MD, Shiffrar M (2009) The visual perception of motion by observers with autism spectrum disorders: a review and synthesis. Psychon Bull Rev 16:761-777. CrossRef Medline

Kanner L (1943) Autistic disturbances of affective contact. Nervous Child 2:217-250. 
Katzner S, Busse L, Carandini M (2011) GABAA inhibition controls response gain in visual cortex. J Neurosci 31:5931-5941. CrossRef Medline

Lappin JS, Tadin D, Nyquist JB, Corn AL (2009) Spatial and temporal limits of motion perception across variations in speed, eccentricity, and low vision. J Vis 9:30.1-30.14. CrossRef Medline

Lord C, Rutter M, Le Couteur A (1994) Autism Diagnostic Interview-Revised: a revised version of a diagnostic interview for caregivers of individuals with possible pervasive developmental disorders. J Autism Dev Disord 24:659-685. CrossRef Medline

Lord C, Risi S, Lambrecht L, Cook EH Jr, Leventhal BL, DiLavore PC, Pickles A, Rutter M (2000) The autism diagnostic observation schedule-generic: a standard measure of social and communication deficits associated with the spectrum of autism. J Autism Dev Disord 30:205-223. CrossRef Medline

Mottron L, Dawson M, Soulières I, Hubert B, Burack J (2006) Enhanced perceptual functioning in autism: an update, and eight principles of autistic perception. J Autism Dev Disord 36:27-43. CrossRef Medline

Nakayama K, Silverman GH (1985) Detection and discrimination of sinusoidal grating displacements. J Opt Soc Am A 2:267-274. CrossRef Medline

Oblak AL, Gibbs TT, Blatt GJ (2010) Decreased GABA(B) receptors in the cingulate cortex and fusiform gyrus in autism. J Neurochem 114: 1414-1423. CrossRef Medline

Pei F, Baldassi S, Norcia A (2012) Visual gain control abnormalities in autism spectrum disorders. Int J Psychophysiol 298-299.

Pellicano E, Gibson L, Maybery M, Durkin K, Badcock DR (2005) Abnormal global processing along the dorsal visual pathway in autism: a possible mechanism for weak visuospatial coherence? Neuropsychologia 43:1044-1053. CrossRef Medline

Plaisted K, O'Riordan M, Baron-Cohen S (1998) Enhanced visual search for a conjunctive target in autism: a research note. J Child Psychol Psychiatry 39:777-783. Medline

Porciatti V, Bonanni P, Fiorentini A, Guerrini R (2000) Lack of cortical contrast gain control in human photosensitive epilepsy. Nat Neurosci 3:259-263. CrossRef Medline

Rubenstein JL, Merzenich MM (2003) Model of autism: increased ratio of excitation/inhibition in key neural systems. Genes Brain Behav 2:255-267. CrossRef Medline

Said CP, Egan RD, Minshew NJ, Behrmann M, Heeger DJ (2013) Normal binocular rivalry in autism: implications for the excitation/inhibition imbalance hypothesis. Vision Res 77:59-66. CrossRef Medline
Samson F, Mottron L, Soulières I, Zeffiro TA (2011) Enhanced visual functioning in autism: An ALE meta-analysis. Hum Brain Mapp.

Scheuffgen K, Happé F, Anderson M, Frith U (2000) High "intelligence," low "IQ"? Speed of processing and measured IQ in children with autism. Dev Psychopathol 12:83-90. CrossRef Medline

Schmeisser MJ, Ey E, Wegener S, Bockmann J, Stempel AV, Kuebler A, Janssen AL, Udvardi PT, Shiban E, Spilker C, Balschun D, Skryabin BV, Dieck St, Smalla KH, Montag D, Leblond CS, Faure P, Torquet N, Le Sourd AM, Toro R, et al. (2012) Autistic-like behaviours and hyperactivity in mice lacking ProSAP1/Shank2. Nature 486:256-260. Medline

Simmons DR, Robertson AE, McKay LS, Toal E, McAleer P, Pollick FE (2009) Vision in autism spectrum disorders. Vision Res 49:2705-2739. CrossRef Medline

Spencer J, O’Brien J, Riggs K, Braddick O, Atkinson J, Wattam-Bell J (2000) Motion processing in autism: evidence for a dorsal stream deficiency. Neuroreport 11:2765-2767. CrossRef Medline

Tadin D, Lappin JS, Gilroy LA, Blake R (2003) Perceptual consequences of centre-surround antagonism in visual motion processing. Nature 424: 312-315. CrossRef Medline

Tadin D, Lappin JS, Blake R (2006a) Fine temporal properties of centersurround interactions in motion revealed by reverse correlation. J Neurosci 26:2614-2622. CrossRef Medline

Tadin D, Kim J, Doop ML, Gibson C, Lappin JS, Blake R, Park S (2006b) Weakened center-surround interactions in visual motion processing in schizophrenia. J Neurosci 26:11403-11412. CrossRef Medline

Tadin D, Silvanto J, Pascual-Leone A, Battelli L (2011) Improved motion perception and impaired spatial suppression following disruption of cortical area MT/V5. J Neurosci 31:1279-1283. CrossRef Medline

Tsai JJ, Norcia AM, Ales JM, Wade AR (2011) Contrast gain control abnormalities in idiopathic generalized epilepsy. Ann Neurol 70:574-582. CrossRef Medline

Tuchman R, Cuccaro M (2011) Epilepsy and autism: neurodevelopmental perspective. Curr Neurol Neurosci Rep 11:428-434. CrossRef Medline

Watson AB, Pelli DG (1983) QUEST: a Bayesian adaptive psychometric method. Percept Psychophys 33:113-120. CrossRef Medline

Weschsler D (1999) WASI: Wechsler abbreviated scale of intelligence. San Antonio, TX: Harcourt.

Whitney D (2002) The influence of visual motion on perceived position. Trends Cogn Sci 6:211-216. CrossRef Medline

Zwaigenbaum L, Bryson S, Rogers T, Roberts W, Brian J, Szatmari P (2005) Behavioral manifestations of autism in the first year of life. Int J Dev Neurosci 23:143-152. CrossRef Medline 